\title{
Synthesis of $\mathrm{LiCoO}_{2}$ Nanoparticles by a Sonochemical Method under the Multibubble Sonoluminescence Conditions
}

\author{
Jong Pil Park, Jea Young Park, Cha Hwan Hwang, Myung-ho Choi, Jee Eon Kim, Kang Min Ok, and Il-Wun Shim* \\ Department of Chemistry, Chung-Ang University, Seoul 156-756, Korea. *E-mail: iwshim@cau.ac.kr \\ Received August 18, 2009, Accepted December 14, 2009
}

\begin{abstract}
$\mathrm{LiCoO}_{2}$, a cathode material for lithium rechargeable batteries, was prepared in a nanoscale through a simple sonochemistry. First, $\mathrm{Co}_{3} \mathrm{O}_{4}$ nanoparticles were prepared by reacting $\mathrm{NaOH}$ and $\mathrm{CoCl}_{2}$ or $\mathrm{CoSO}_{4}$ with a sonochemical method, operated at $20 \mathrm{kHz}$ and $220 \mathrm{~W}$ for $20 \mathrm{~min}$, very powerful multibubble sonoluminescence conditions for chemical reactions. Second, $\mathrm{LiOH}$ was coated onto the $\mathrm{Co}_{3} \mathrm{O}_{4}$ nanoparticles by the same method as above. Finally, $\mathrm{LiCoO}_{2}$ nanoparticles of about $10 \sim 30 \mathrm{~nm}$ size in diameter were obtained by the thermal treatment of the resulting LiOH-coated $\mathrm{Co}_{3} \mathrm{O}_{4}$ nanoparticles at $500{ }^{\circ} \mathrm{C}$ for $3 \mathrm{hr}$. This synthetic process is relatively quite mild and simple compared to the known method for the synthesis of $\mathrm{LiCoO}_{2}$ nanoparticles. The materials synthesized were characterized by infrared spectroscopy, X-ray diffraction, inductively coupled plasma spectrometer, and high resolution-transmission electron microscopy analyses.
\end{abstract}

Key Words: $\mathrm{Co}_{3} \mathrm{O}_{4}$ nanoparticles, $\mathrm{LiOH}$-coated $\mathrm{Co}_{3} \mathrm{O}_{4}$ nanoparticles, $\mathrm{LiCoO}_{2}$ nanoparticles

\section{Introduction}

Lithium secondary batteries are being used worldwide as ubiquitous energy storage devices from mobile phones to electric vehicles. ${ }^{1}$ Among the lithium battery electrode materials, LiCo$\mathrm{O}_{2}$ has been the most attractive due to the best performance in terms of high specific energy density and excellent cycle life, so that it was already commercialized as a cathode material. ${ }^{1,2}$ Numerous investigations on the syntheses and electrochemical properties of $\mathrm{LiCoO}_{2}$ materials have been made to improve its performance, ${ }^{3-5}$ and most of the works focused on the preparation of $\mathrm{LiCoO}_{2}$ particles with various sizes and shapes through conventional solid-state reactions, ${ }^{6,7}$ and solution-assisted methods such as sol-gel, ${ }^{8,9}$ hydrothermal, ${ }^{10}$ emulsion drying, ${ }^{11}$ and other method. ${ }^{12}$ In general, however, it was hard to make homogeneous $\mathrm{LiCoO}_{2}$ nanoparticles; it typically required wearisome conditions, such as very high temperature, long producing time, and so on. To overcome such problems, many coating methods onto inorganic oxide nanoparticles, resulting into various core/ shell type nanocrystals, were applied for its preparation.

The core/shell type materials were extensively studied through different methods, such as hydrothermal synthetic method, microwave, and sonochemistry. ${ }^{13-15}$ Especially in the sonochemical method, it is relatively easy to control the coating depth of target materials by adjusting reaction conditions such as the amount of reactants and/or the sonication time. ${ }^{16,17}$ In particular, the multi-component particles with core/shell structure, which can be prepared at the multibubble sonoluminescence condition, have recently drawn special attention due to their fascinating properties for various applications in catalysts, ${ }^{17}$ luminescence ${ }^{18}$ and lithium-ion batteries. ${ }^{19}$

The sonochemistry is an application of sonoluminescence which is a light emission phenomenon associated with the collapse of a gas bubble oscillating under an ultrasonic field. The intense local heating and high pressure inside the bubbles and liquid adjacent the bubble walls from such collapse can give rise to unusual effects in chemical reactions ${ }^{20}$ and the sonochemical process has been proven to be a useful technique to make novel materials with unusual properties. The estimated temperature and pressure in liquid zone around the collapsing bubble with equilibrium radius $5 \mu \mathrm{m}$, generated in a sonochemical reactor at a driving frequency of $20 \mathrm{kHz}$ with an input power of $179 \mathrm{~W}$ were about $1000{ }^{\circ} \mathrm{C}$ and $500 \mathrm{~atm}$, respectively. ${ }^{21}$ The sonochemical reaction system in this study was operated at 20 $\mathrm{kHz}$ and $220 \mathrm{~W}$, which produces very powerful multibubble sonoluminescence conditions compared to other typical ultrasound irradiation processes. . $^{21,22}$

We report a new method for the preparation of homogeneous $\mathrm{LiCoO}_{2}$ nanoparticles under relatively mild conditions. As shown in Scheme 1, first, $\mathrm{NaOH}$ and $\mathrm{CoCl}_{2}$ or $\mathrm{CoSO}_{4}$ were reacted to prepare $\mathrm{Co}_{3} \mathrm{O}_{4}$ nanoparticles by sonochemistry. Second, $\mathrm{LiOH}$-coated $\mathrm{Co}_{3} \mathrm{O}_{4}$ nanoparticles was prepared using $\mathrm{Co}_{3} \mathrm{O}_{4}$ and $\mathrm{LiOH}$ by the same sonochemical method as above. Finally, they were transformed into $\mathrm{LiCoO}_{2}$ nanoparticles by thermal heating at $500{ }^{\circ} \mathrm{C}$ for $3 \mathrm{hr}$.

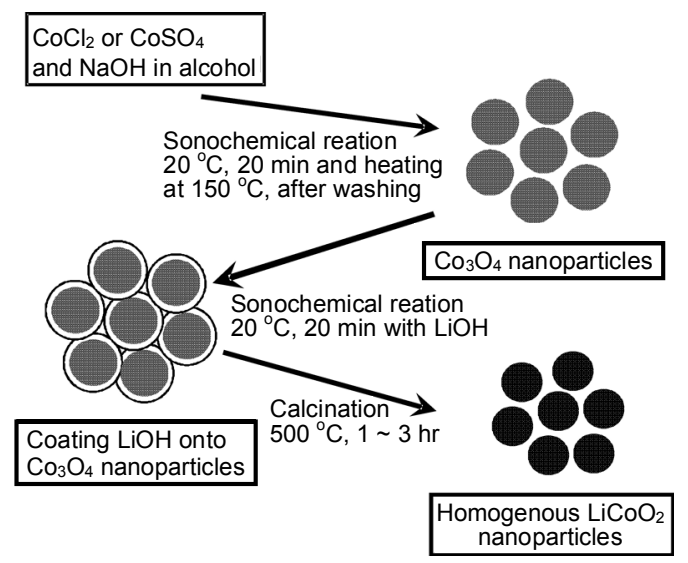

Scheme 1. Three step method for $\mathrm{LiCoO}_{2}$ nanoparticles preparation through sonochemistry. 


\section{Experimental Details}

All solvents were refluxed over molecular sieves $3 \AA$ (pellets, $3.2 \mathrm{~mm}$ ) to remove water molecules and then distilled before using them. An experimental apparatus described in our previous papers ${ }^{16}$ for sonochemistry system was used. It consists of a cylindrical quartz cell into, which a $5 \mathrm{~mm}$ diameter titanium horn (Misonix XL2020, USA) is inserted. The solvent in the cell was kept at $1.4 \mathrm{~atm}$ with argon gas and the temperature of the solution inside the cell was kept to around $20{ }^{\circ} \mathrm{C}$ by a circulating water, which was found to be optimal condition for the coating process. $^{13}$

Preparing the $\mathrm{CO}_{3} \mathrm{O}_{4}$ nanoparticles. $\mathrm{Co}_{3} \mathrm{O}_{4}$ nanoparticles were prepared by reacting $\mathrm{NaOH}(2 \mathrm{mmol})$ and $\mathrm{CoCl}_{2}$ or $\mathrm{CoSO}_{4}(1$ $\mathrm{mmol})$ with a $2: 1$ ratio in methanol or ethanol $(13 \mathrm{~mL})$ through a one pot reaction under the described sonochemical conditions for $20 \mathrm{~min}$. The resulting products were washed 3 times using methanol or ethanol, and then they were heated at $150{ }^{\circ} \mathrm{C}$ for 1 hour.

LiOH coating onto $\mathrm{Co}_{3} \mathrm{O}_{4}$ nanoparticles. $\mathrm{Co}_{3} \mathrm{O}_{4}$ nanoparticles were coated with $\mathrm{LiOH}$ through a one pot reaction under the same sonochemical conditions as above since the $\mathrm{LiOH}$-coated $\mathrm{Co}_{3} \mathrm{O}_{4}$ particles are very likely to be a useful precursor for the preparation of $\mathrm{LiCoO}_{2}$ nanoparticles. In order to find best coating depth for the preparation of $\mathrm{LiCoO}_{2}$ nanoparticles, several different reaction ratios between $\mathrm{LiOH}$ and $\mathrm{Co}_{3} \mathrm{O}_{4}$ such as $1: 1$, 1.5:1, and 2:1 were tried. Each $\mathrm{LiOH} \cdot \mathrm{H}_{2} \mathrm{O}$ and $\mathrm{Co}_{3} \mathrm{O}_{4}$ in methyl alcohol $(13 \mathrm{~mL})$ solution was sonicated at the aforementioned conditions for $20 \mathrm{~min}$. The color of $\mathrm{LiOH}$-coated nanoparticles was gray and the resulting particles were washed by DI-water, alcohol, acetone in order and dried at vacuum oven at $60{ }^{\circ} \mathrm{C}$ for $12 \mathrm{hr}$.

Preparation of $\mathrm{LiCoO}_{2}$ nanoparticles. $\mathrm{LiOH}$-coated $\mathrm{Co}_{3} \mathrm{O}_{4}$ nanoparticles as a precursor were heated at $500{ }^{\circ} \mathrm{C}$ for $1 \sim 3 \mathrm{hr}$ for the formation of $\mathrm{LiCoO}_{2}$ nanoparticles. Only the coated precursor from the reaction ratio 2:1 between $\mathrm{LiOH}$ and $\mathrm{Co}_{3} \mathrm{O}_{4}$ was transformed into the $\mathrm{LiCoO}_{2}$ nanoparticles with proper stoichiometry. The resulting materials were characterized by various instruments, such as X-ray diffractometer (Scintag XDS-2000), infrared spectroscopy(varian FTS 1000), field emission-transmission electron microscope(Techani G2 F30), energy dispersive X-ray spectroscopy, and inductively coupled plasma spectrometer(JY-Ultima-2).

\section{Result and Discussion}

Figure 1 and 2 show the transmission electron microscopic image and XRD pattern of $\mathrm{CO}_{3} \mathrm{O}_{4}$ nanoparticles prepared through the aforementioned sonochemical reaction. The yield is $97 \%$. It is interesting to note that there were no other compounds such as $\mathrm{CoO}$ or $\mathrm{Co}_{2} \mathrm{O}_{3}$. On the other hand, there was a mixture of various cobalt oxides at the lower sonochemical conditions. The size of the bare $\mathrm{Co}_{3} \mathrm{O}_{4}$ nanoparticles was about 10 to $40 \mathrm{~nm}$ with quite narrow size distribution. In Figure 2, the XRD pattern of $\mathrm{CO}_{3} \mathrm{O}_{4}$ nanoparticles indicates a cubic phase ${ }^{23}$ and the XRD pattern of the $\mathrm{LiOH}$-coated $\mathrm{Co}_{3} \mathrm{O}_{4}$ nanoparticles indicates that the $\mathrm{LiOH}$ is in a tetragonal phase ${ }^{24}$ with most intense picks at $2 \theta=32.9^{\circ}$ corresponding to (101) planes. The relatively low intensities of

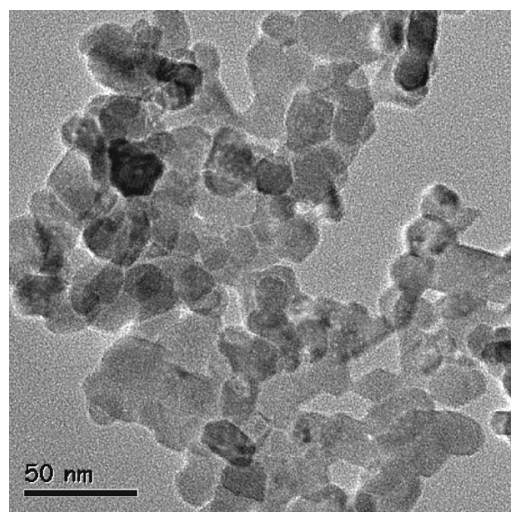

Figure 1. TEM image of $\mathrm{Co}_{3} \mathrm{O}_{4}$ nanoparticles prepared under the described sonochemical conditions.

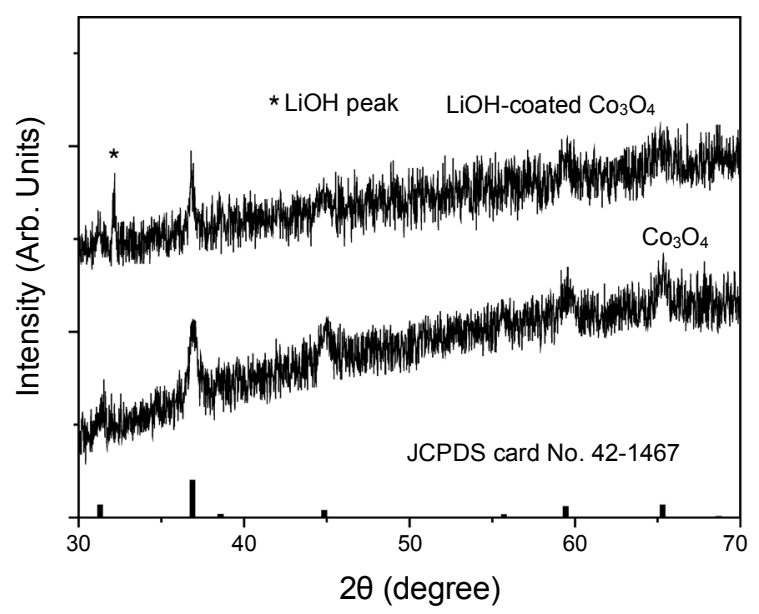

Figure 2. XRD data of $\mathrm{Co}_{3} \mathrm{O}_{4}$ and $\mathrm{LiOH}$-coated $\mathrm{Co}_{3} \mathrm{O}_{4}$ nanoparticles. The perpendicular bars at the bottom of the graph are from the reference of Powder Diffraction File of $\mathrm{Co}_{3} \mathrm{O}_{4}$.

picks are assumed to arise from the fact that the particles are nano-sized and the $\mathrm{LiOH}$ is thinly coated on $\mathrm{Co}_{3} \mathrm{O}_{4}$. In addition, its IR spectra showed various characteristic peaks due to $\mathrm{LiOH}$ at $3438,2585,2365,1806,1637,1512,1436,1085,866,733$, and $633 \mathrm{~cm}^{-1}$.

Figure 3 shows the high resolution transmission electron microscopic image of the $\mathrm{LiOH}$-coated $\mathrm{Co}_{3} \mathrm{O}_{4}$ nanoparticles, indicating that $\mathrm{LiOH}$ is evenly coated on the surface of $\mathrm{Co}_{3} \mathrm{O}_{4}$. The coating depth of $\mathrm{LiOH}$ on $\mathrm{Co}_{3} \mathrm{O}_{4}$ from the reaction ratio of 2:1 between $\mathrm{LiOH}$ and $\mathrm{CoCl}_{2}$ was found to be about $3 \sim 5 \mathrm{~nm}$ range. It should be noted that rapid syntheses with very homogeneous size of $\mathrm{LiOH}$ and subsequent coating of the particles onto $\mathrm{Co}_{3} \mathrm{O}_{4}$ nanoparticles under the described sonochemical conditions might be attributed to the existence of transient supercritical state in the liquid layer adjacent to the bubble wall around the collapse point. ${ }^{26}$

Only the precursor with the reactant ratio of $2: 1$ for $\mathrm{LiOH}$ and $\mathrm{Co}_{3} \mathrm{O}_{4}$ was transformed into $\mathrm{LiCoO}_{2}$ nanoparticles by thermal treatments at $300 \sim 500{ }^{\circ} \mathrm{C}$ for $1 \sim 3 \mathrm{hr}$. In the cases of other precursors with the reactant ratio of $1: 1$ or $1.5: 1$ for $\mathrm{LiOH}$ and $\mathrm{Co}_{3} \mathrm{O}_{4}$, there was unreacted $\mathrm{Co}_{3} \mathrm{O}_{4}$ in their XRD patterns. Figure 4 shows XRD data of $\mathrm{LiCoO}_{2}$ nanoparticles. According to in- 


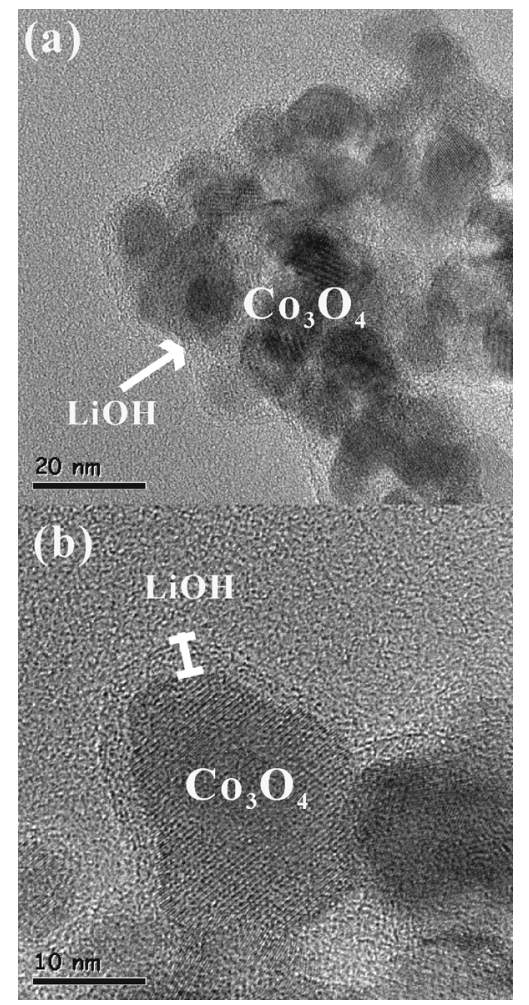

Figure 3. TEM images of LiOH-coated $\mathrm{Co}_{3} \mathrm{O}_{4}$ nanoparticles prepared under the described sonochemical conditions.

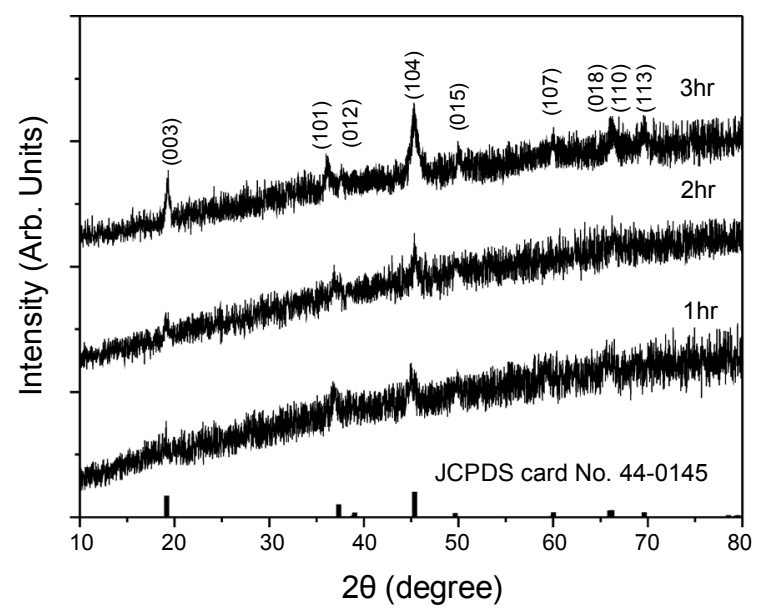

Figure 4. XRD data of $\mathrm{LiCoO}_{2}$ nanoparticles prepared at $500{ }^{\circ} \mathrm{C}$ for $1 \sim 3 \mathrm{hr}$. The perpendicular bars at the bottom of the graph are from the reference of Powder Diffraction File of $\mathrm{LiCoO}_{2}$.

creasing temperature, the peak intensity becomes stronger. The XRD pattern of the $\mathrm{LiCoO}_{2}$ nanoparticles indicates a cubic phase $^{27}$ with most intense peaks at $2 \theta=19.2^{\circ}, 37.3^{\circ}, 39.0^{\circ}, 45.4^{\circ}$, $49.7^{\circ}, 60.0^{\circ}, 66.0^{\circ}, 66.2^{\circ}$, and $69.6^{\circ}$, corresponding to $(003)$, (101), (012), (104), (015), (107), (018), (110), and (113) planes.

Figure 5 shows the high resolution transmission electron microscopic image of $\mathrm{LiCoO}_{2}$ nanoparticles. Their size was about 10 to $30 \mathrm{~nm}$ in diameter, which was a little bit smaller to that of $\mathrm{Co}_{3} \mathrm{O}_{4}$ nanoparticles. These nanoparticles are very pure in phase and quite homogeneous in their sizes and their shapes. In addi-

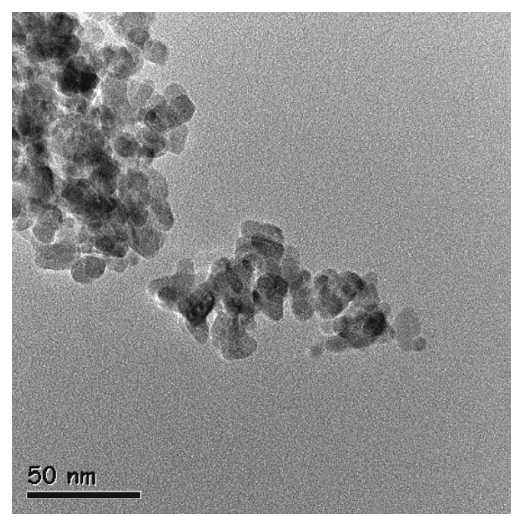

Figure 5. TEM image of $\mathrm{LiCoO}_{2}$ nanoparticles prepared at $500{ }^{\circ} \mathrm{C}$ for $3 \mathrm{hr}$.

tion, EDX analyses show that the atomic percents of $\mathrm{Co}$ and $\mathrm{O}$ are 33.50 and $66.49 \%$ and ICP analyses also show $\mathrm{Li}$ : Co ratio of $1.002: 1.000$. These results indicate the exact stoichiometric elemental ratio of $\mathrm{LiCoO}_{2}$ nanoparticles.

\section{Conclusions}

In conclusion, $\mathrm{Co}_{3} \mathrm{O}_{4}$ nanoparticles were prepared by a one pot sonochemical reaction at room temperature using $\mathrm{NaOH}$ and $\mathrm{CoCl}_{2}$ or $\mathrm{CoSO}_{4}$ in water. Subsequently, $\mathrm{LiOH}$-coated $\mathrm{Co}_{3}-$ $\mathrm{O}_{4}$ nanoparticles were prepared by the same methods using $\mathrm{LiOH}$ and prepared $\mathrm{Co}_{3} \mathrm{O}_{4}$ nanoparticles. The crystalline phase of the coated $\mathrm{LiOH}$ on $\mathrm{Co}_{3} \mathrm{O}_{4}$ was tetragonal and the depth of coated $\mathrm{LiOH}$ onto $\mathrm{Co}_{3} \mathrm{O}_{4}$ nanoparticles was found to be about 3 - $5 \mathrm{~nm}$. As a precursor, the $\mathrm{LiOH}$-coated $\mathrm{Co}_{3} \mathrm{O}_{4}$ nanoparticles from the reaction ratio of 2:1 between $\mathrm{LiOH}$ and $\mathrm{Co}_{3} \mathrm{O}_{4}$ were used for the synthesis $\mathrm{LiCoO}_{2}$ nanoparticles by heating at $500{ }^{\circ} \mathrm{C}$ for $3 \mathrm{~h}$. These are the mildest conditions for $\mathrm{LiCoO}_{2}$ nanoparticle praperations. $^{1-7}$

Acknowledgments. This research was supported by the Chung-Ang University Research Scholarship Grant for J.Y. Park and C. H. Hwang in 2009.

\section{Reference}

1. Tarascon, J. M.; Armand, M. Nature 2001, 414, 359.

2. Sun, Y. K. J. Mater. Sci. 1996, 14, 3617.

3. Li, L.; Meyer, W. H.; Wegner, G.; Wohlfahrt-Mehrens, M. Adv. Mater. 2005, 17, 984.

4. Chen, Z.; Dahn, J. R. Electrochem. Solid-State Lett. 2004, 7, A11.

5. Liu, J.; Wen, Z.; Gu, Z.; Wu, M.; Lin, Z. J. Electrochem. Soc. 2002, 149, A1405.

6. Reimers, J. N.; Dahn, J. R. J. Electrochem. Soc. 1992, 139, 2091.

7. Ohzuku, T.; Ueda, A. J. Electrochem. Soc. 1994, 141, 2972.

8. Sun, Y. K.; Oh, I. H.; Hong, S. A. J. Mater. Sci. 1996, 31, 3617.

9. Yoon, W. S.; Kim, K. B. J. Power Sources 1999, 81-82, 517.

10. Tabuchi, M.; Ado, K.; Kobayashi, H.; Sakaebe, H.; Kageyama, H.; Masquelier, C.; Yonemura, M.; Hirano, A. J. Mater. Chem. 1999, 9, 199.

11. Han, C. H.; Yeh, P. Y. J. Mater. Chem. 2000, 10, 599.

12. Ying, J.; Jiang, C.; Wan, C. J. Power Sources 2004, 129, 264.

13. Kim, M. R.; Ahn S. J.; Jang, D. J. J. Nanosci. Nanotech. 2006, 6, 180.

14. Shao, M.; Li, Q.; Xie, B.; Wu, J.; Qian, Y. Mater. Chem. Phys. 
2002, 78, 288.

15. Dahs, N. A.; Gedanken, A. Appl. Phys. Lett. 1998, 72, 2514.

16. Lee, S. S.; Seo, K. W.; Yoon, S. H.; Shim, I. W.; Byun, K. T.; Kwak, H.-Y. Bull. Korean Chem. Soc. 2005, 26, 1579.

17. Kim, H-W.; Kang, K-I.; Kwak, H-Y. Int. J. Hydrogen Energy 2009 , 34, 3351 .

18. Yang, P.; Quan, Z.; Li, C.; Yang, J.; Wang, H.; Liu, X.; Lin, J. J. Solid State Chem. 2008, 181, 1943.

19. Lio, H.; Wang, G.; Wang, J.; Wexler, D. Electrochem. Commun. 2008, 10, 1897.

20. Suslick, K. S. Science 1990, 247, 1439.

21. Kwak, H. Y.; Yang, H. J. Phys. Soc. Jpn. 1995, 64, 1980.

22. Kim, K. Y.; Byun, K.; Kwak, H. Chem. Eng. J. 2007, 132, 125.
23. Powder Diffraction File, Joint Committee on Powder Diffraction Standard, ICDD, September 1995, Cards No. 42-1467. Version 1.10 .

24. Powder Diffraction File, Joint Committee on Powder Diffraction Standard, ICDD, September 1995, Cards No. 32-0564. Version 1.10 .

25. Nyquist, R. A.; Kagel, R. O. The handbook of Infrared and Raman Spectra of Inorganic Compounds and Organic Salts; Academic Press: 1997; Vol. 4, pp 215.

26. Huang, H.; Hoffmann, M. R. J. Phys. Chem. A 1999, 103, 2734.

27. Powder Diffraction File, Joint Committee on Powder Diffraction Standard, ICDD, September 1995, Cards No. 44-0145. Version 1.10 . 